\title{
Synthesis and Lithographic Characterization of Poly(6-vinyluracil) Derivative
}

\author{
Takanori Sugiki and Yoshiaki Inaki * \\ Central Reseach Laboratory, Nichiban Co. Ltd., Anjo, Aichi, \\ *Department of Material and Life Science, Graduate School of Engineering, \\ Osaka University. Yamadaoka 2-1,Suita, Osaka 565-0871, Japan.
}

\begin{abstract}
Enol ether derivative of poly(6-vinyluracil) was synthesized. The polymer released completely the tert-butyl groups above $190^{\circ} \mathrm{C}$ and gave poly(6-vinyluracil) which was stable up to $350^{\circ} \mathrm{C}$. The resist film as spin coated from chloroform solution containing photo-acid generator released completely the tert-butyl groups after UV light irradiation followed by post exposure baking. Solubility of the obtained polymer containing uracil unit was significantly different from the original polymer containing alkoxy units in both polar (TMAH aq) and nonpolar (anisole) solvents as developer. The resist film was found to have high sensitivity and high contrast as both positive and negative type deep-UV resist materials.
\end{abstract}

Keywords: poly(6-vinyluracil), tautomerism, deep-UV resist

\section{Introduction}

For recent years, we have studied photo-responsive materials using synthetic nucleic acid analogs. Thymine bases in DNA undergo [2+2] cycloaddition reaction by irradiation at $\lambda \max (270 \mathrm{~nm})$ of thymine base, and the photodimer readily reverse to monomer by UV light at shorter wavelength of $240 \mathrm{~nm}$ [1, 2]. We had reported that the synthesis of a variety of thymine derivatives and these reversible photodimerizations can be applied to photo recording systems [3-7] and photo resist materials [8-21].

Uracil, which is also one of pyrimidine bases in RNA, is known to show the structure in keto-enol tautomerism, and mostly exists in keto-form. Dialkoxypyrimidines, enol ether derivatives of uracil, therefore easily afford uracil by tautomerization with an acid catalyst (Figure 1). Previously, the polyethers containing pyrimidine and tert-alkyl units in the main chain were prepared, and the properties of these poly-

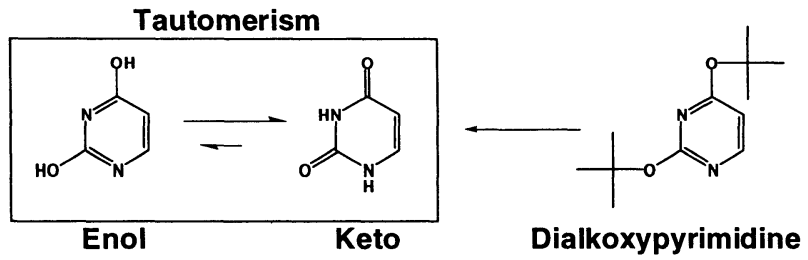

Fig. 1. Keto-enol tautomerism of uracil, and dialkoxypyrimidine derivative.

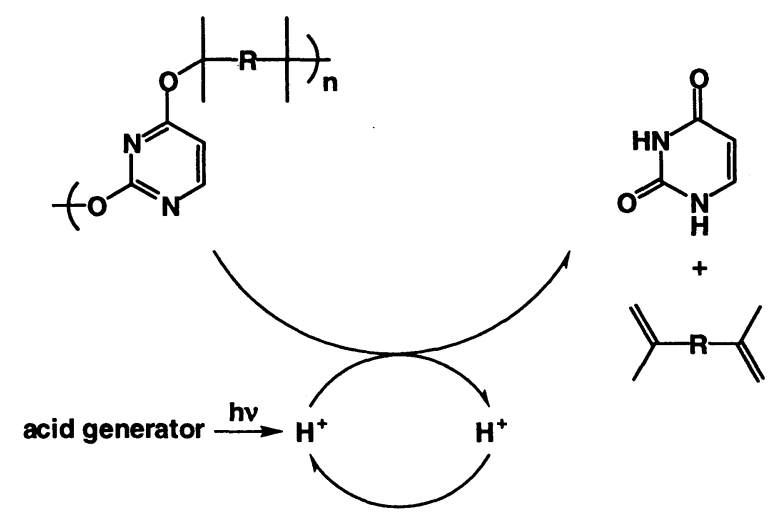

Fig. 2. Chemical amplification of dialkoxypyrimidine polymer [22]. $\mathrm{R}=$ phenyl.

mers were studied as chemically amplified deep-UV resists [22] (Figure 2). The polyether had high sensitivity and high contrast due to effective tautomerism by photo-acid generator. The ether bonds decomposed effectively by acid. Synthesis of the polyether by Williamson reaction, however, was difficult to yield high molecular weight polymer. In general, the polymerization of a vinyl compound is easier to control the molecular weight relative to a polycondensation such as the polyether synthesis.

In this paper, we report the synthesis and lithographic characterization of enol ether derivative of poly(6-vinyluracil). The polymer is proposed as a new strategy for a chemically amplified deep-UV resist material. 


\section{Experimental}

\section{1. Materials (Scheme 1)}

6-Methyluracilyl triphenylphosphonium chloride (2)

Into a solution of 6-(chloromethyl)uracil (1)(32

$\mathrm{g}, 0.2 \mathrm{~mol}$ ) in $N, N$-dimethylformamide (DMF, 200 $\mathrm{ml})$, triphenylphosphine $(80 \mathrm{~g}, 0.3 \mathrm{~mol})$ was added. The mixture was stirred at $100^{\circ} \mathrm{C}$ for $3 \mathrm{~h}$ under nitrogen. The resulting mixture was cooled to room temperature, and deposited white solid was filtered and washed with diethyl ether. The product was recrystallized from ethanol to give 2 ( $88 \mathrm{~g}, 94 \%$ yield), containing 1 equivalent of ethernol as co-crystal.

${ }^{1} \mathrm{H}-\mathrm{NMR}\left(270 \mathrm{MHz}, \mathrm{DMSO}-\mathrm{d}_{6}\right) 1.05$ (d, 3H, $\mathrm{CH}_{3} \mathrm{CH}_{2} \mathrm{OH}$ ), 3.44 (q, $\left.2 \mathrm{H}, \mathrm{CH}_{3} \mathrm{CH}_{2} \mathrm{OH}\right), 4.39(\mathrm{~s}, 1 \mathrm{H}$, $\left.\mathrm{CH}_{3} \mathrm{CH}_{2} \mathrm{OH}\right), 5.07(\mathrm{~s}, 1 \mathrm{H}, 5-\mathrm{H}), 5.14\left(\mathrm{~d}, 2 \mathrm{H}, \mathrm{CH}_{2}\right)$, 7.76-8.10 (m, 15H, $\left.\mathrm{C}_{6} \mathrm{H}_{5}\right), 11.06$ and $11.13(\mathrm{~s}, 2 \mathrm{H}$, $2 \mathrm{NH})$.

6-Vinyluracil (3)

A mixture of the phosphonium chloride derivative $2\left(2.1 \mathrm{~g}, 5.0 \mathrm{mmol}\right.$, dried over $\mathrm{P}_{2} \mathrm{O}_{5}$ at $100^{\circ} \mathrm{C}$ for $20 \mathrm{~h})$ and paraformaldehyde $(0.75 \mathrm{~g}, 25 \mathrm{mmol}$, dried over $\mathrm{P}_{2} \mathrm{O}_{5}$ at $100^{\circ} \mathrm{C}$ for $20 \mathrm{~h}$ ) was suspended in dry DMF $(100 \mathrm{ml})$. To the stirred suspension was added dropwise under nitrogen a solution of sodium ethoxide (prepared from $0.5 \mathrm{~g}$ of sodium metal in 30 $\mathrm{ml}$ of absolute ethanol). After all the sodium ethoxide was added (30 min), the suspension was stirred at room tenperature under nitrogen for $39 \mathrm{~h}$ and evaporated to dryness. Water $(20 \mathrm{ml})$ was added into the residual solid, and insoluble solid (triphenylphosphine oxide) was removed by filteration. Hydrochloric acid $(1 \mathrm{~N})$ was added dropwise to the filtrate with stirring at $0^{\circ} \mathrm{C}$ for neutralization. The precipitated white solid was collected, and was washed with water and diethyl ether, and was recrystallized from acetic acid to give $3(0.45 \mathrm{~g}, 65 \%$ yield $)$.

${ }^{1} \mathrm{H}-\mathrm{NMR}$ (DMSO-d D $_{6} 5.64$ (s, 1H, 5-H), 5.65 (d, 1H, $=\mathrm{CH}_{2}$ cis $), 6.25\left(\mathrm{~d}, 1 \mathrm{H},=\mathrm{CH}_{2}\right.$ trans $), 6.38(\mathrm{q}, 1 \mathrm{H}$, $\mathrm{RCH}=\mathrm{C}), 10.86,11.03(2 \mathrm{~s}, 2 \mathrm{H}, 2 \mathrm{NH}), \mathrm{Jgem}=0.7 \mathrm{~Hz}$, Jtrans $=17.7 \mathrm{~Hz}$, Jcis $=10.7 \mathrm{~Hz}$.

Anal. Calcd. for $\mathrm{C}_{6} \mathrm{H}_{6} \mathrm{~N}_{2} \mathrm{O}_{2}: \mathrm{C}, 52.17 ; \mathrm{H}, 4.38 ; \mathrm{N}$, 20.28\%, Found: C, 51.57; H, 4.35; N, 20.18\%.

2,4-Dichloro-6-vinylpyrimidine (4)

To 6-vinyluracil 3 (1.4 g, $10 \mathrm{mmol})$ was added phosphorus oxychloride $(20 \mathrm{ml}, 220 \mathrm{mmol})$ and $N, N$ diethylaniline $(2.4 \mathrm{ml}, 15 \mathrm{mmol})$. The mixture was refluxed for $1 \mathrm{~h}$ under nitrogen, and the volatile components were removed under diminished pressure. The residual brown fluid was poured into crushed ice-water. Ether extract was washed with cooled water 3 times, dried on $\mathrm{MgSO}_{4}$, and ether was removed to give crude 4 (light yellowish oil, $1.5 \mathrm{~g}$, $86 \%$ yield). Because the compound decomposed slowly in air, the compound was used for the following reaction without further purification.

${ }^{1} \mathrm{H}-\mathrm{NMR}\left(\mathrm{CDCl}_{3}\right) 5.84\left(\mathrm{q}, 1 \mathrm{H},=\mathrm{CH}_{2} \mathrm{cis}\right), 6.58(\mathrm{q}$, $1 \mathrm{H},=\mathrm{CH}_{2}$ trans $), 6.68(\mathrm{q}, 1 \mathrm{H}, \mathrm{RCH}=\mathrm{C}), 7.23(\mathrm{~s}, 1 \mathrm{H}$, $5-\mathrm{H})$, Jgem $=2.0 \mathrm{~Hz}$, Jtrans $=17.1 \mathrm{~Hz}$, Jcis $=9.3 \mathrm{~Hz}$.

Poly(6-vinylpyrimidine) derivative (6)

The compound $4(1.5 \mathrm{~g}, 8.6 \mathrm{mmol})$ was dissolved in dry THF $(50 \mathrm{ml})$, and potassium tert-butoxide (1.0 $\mathrm{M}$ THF solution, $0.18 \mathrm{ml}$ ) was added to the solution at $-78^{\circ} \mathrm{C}$ with stirring. After the solution was stirred for $3 \mathrm{~h}$ at $-78^{\circ} \mathrm{C}$, potassium tert-butoxide (1.0 M THF solution, $50 \mathrm{ml}$ ) was added. The temperature of the mixture was raised slowly to room temperature, and stirred for 1 week. After the solvent was removed, cooled water (ca. $100 \mathrm{ml}$ ) was added to the residue, and insolved brown solid was collected and washed with water. The brown solid was dissolved in a small amount of chloroform and washed with water 3 times. After the solution was dried on $\mathrm{MgSO}_{4}$ and evaporated, the brown solid was dissolved in methanol, and the solution was poured into $10 \%$ aqueous methanol. The precipitated solid was collected and reprecipitated repeatly until monomer and potassium chloride were removed completely to give the polymer $6(1.6 \mathrm{~g})$.

IR ( $\left.\mathrm{cm}^{-1}\right): 2962,2925,1675,1585,1560,1480,1460$, $1435,1410,1400,1380,1255$, and 1175.

Anal. Calcd. for $25 \%$ chloride units remaining: $\mathrm{C}$, $61.31 ; \mathrm{H}, 7.38 ; \mathrm{N}, 12.28 \%$, Found: C, 61.00; H, 7.32; $\mathrm{N}, 12.18 \%$.

\section{2. Preparation of resist film}

The polymer $6(90 \mathrm{mg})$ and a photo-acid generator (triphenylsulfonium triflate: TPS, $10 \mathrm{mg}$ ) were dissolved in chloroform $(1.0 \mathrm{ml})$, and the solution was spin coated on a HMDS-treated silicon wafer presented by Shin-Etsu Chemical Co. Ltd., and prebaked at $150^{\circ} \mathrm{C}$ for $10 \mathrm{sec}$ to give a $1 \mu \mathrm{m}$ thickness of resist film.

\section{3. Lithgraphic Evaluation}

The resist film was irradiated by deep-UV light at $250 \mathrm{~nm}$. After the irradiated resist film was post baked, the film was developed with $3.0 \mathrm{wt} \%$ of TMAH (tetramethylammonium hydroxyde) aqueous solution or anisole for $1 \mathrm{~min}$. The remaining film thickness was calculated from the absorbance of IR spectra related with measuerment by SEM.

\subsection{Apparatus}

The molecular weight determination of the polymer 6 was made by gel permeation chromatography (GPC) using a Showa Denko Shodex A-80M col- 
<smiles>O=c1cc(CCl)[nH]c(=O)[nH]1</smiles>

1<smiles>CCO[C@@H](OC)c1cc(=O)[nH]c(=O)[nH]1</smiles>

$\underline{2}$

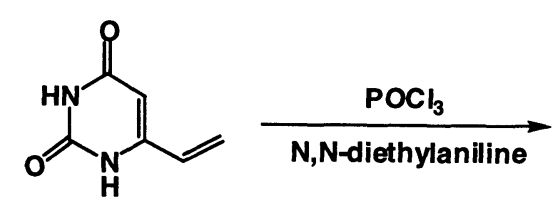

$\underline{3}$

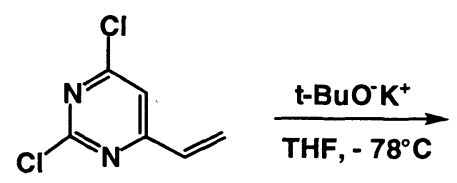

$\underline{4}$<smiles>CCCC(C)C(C)C</smiles>

$\underline{5}$

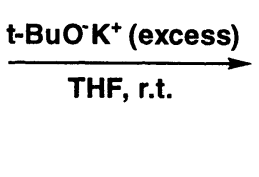

\section{Scheme 1.}

umns at $40^{\circ} \mathrm{C}$ in tetrahydrofuran. Thermal analyses were performed on a SEIKO SSC/580 thermal analyzer at a heating rate of $5^{\circ} \mathrm{C} / \mathrm{min}$ for $\mathrm{TGA}$ and $10^{\circ} \mathrm{C} /$ min for DSC under inert atmosphere. The ${ }^{1} \mathrm{H}-\mathrm{NMR}$ spectra (270 MHz) were measured on a JOEL GSX FT NMR spectrometer using tetramethylsilane as internal standard. The elemental analyses were performed by the Analytical Center of Osaka University. The IR spectra were measured on a Nicolet SDXC FT-IR spectrometer. The irradiation of deepUV light at $250 \mathrm{~nm}$ to the resist film was carried out a JASCO CRM-FA Spectro Irradiator.

\section{Results and Discussion}

3. 1. Synthesis of Enol Ether Derivative of Poly(6vinyluracil)

Enol ether derivative (6) of poly(6-vinyluracil) was prepared according to Scheme 1 . Wittig reaction of 6-(chloromethyl)uracil (1) gave 6-vinyluracil (3). The reaction of 6-vinyluracil with phosphorus oxychloride afforded 2,4-dichloro-6-vinylpyrimidine (4). Anionic polymerization of the monomer 4 was carried out by catalytic amount of potassium tert-butoxide at $-78^{\circ} \mathrm{C}$ for $3 \mathrm{~h}$ to give the polymer 5 . Finaly, Williamson reaction of the polymer 5 with excess potassium tert-butoxide gave the polymer 6 . The polymer 6 was found to have still about $25 \%$ chloride units from elementary analysis, and molecular weight of 36,000 (polystyrene-equivalent) from GPC measurement.

\section{2. Thermal Analysis}

DSC measurement of polymer 6 was achieved (Figure 3). In the first run, the sample of polymer 6 was measured in the range of room temperature to $250^{\circ} \mathrm{C}$. In the seconnd run, the cooled sample was measured

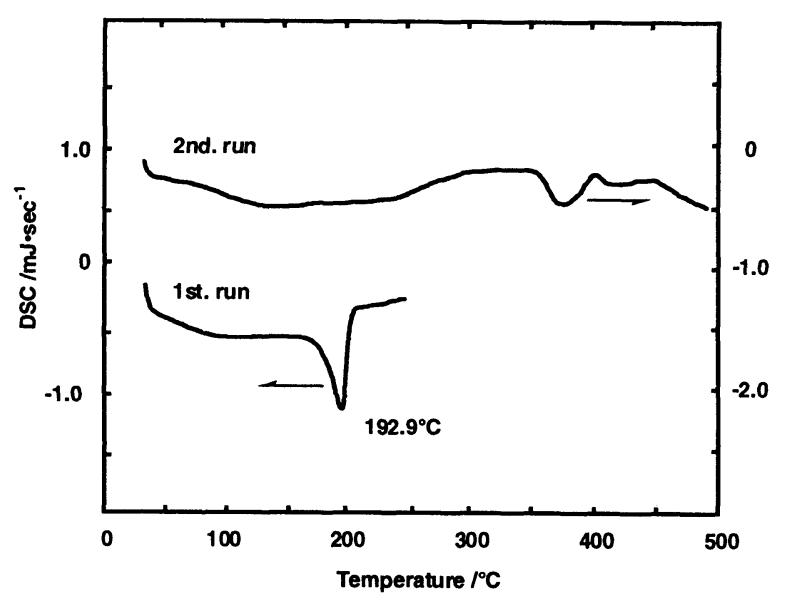

Fig. 3. DSC curves of polymer 6.

again from room temperature to $500^{\circ} \mathrm{C}$. In the first measurement, a sharp endothermic peak was observed around $193^{\circ} \mathrm{C}$. However, there was no peak in the second measurement. The fact suggests that the endothermic peak would not be due to a change of the higher structure or a phase transition, but a change of the chemical structure or a decomposition.

As shown in TGA curve of polymer 6 (Figure 4). the polymer was stable to about $150^{\circ} \mathrm{C}$. The great decrease of the weight was observed around $190^{\circ} \mathrm{C}$. The weight loss at $190^{\circ} \mathrm{C}$ was in fair agreement with the calculate value of tert-butyl group. The IR spectra of the polymer 6 before and after heating at $200^{\circ} \mathrm{C}$ for $3 \mathrm{~min}$ are shown in Figure 5. After heating, the absorbances of tert-butyl group (2962 and $1365 \mathrm{~cm}^{-}$ $\left.{ }^{1}\right)$ disappeared, and new peaks of carbonyl group $\left(1720 \mathrm{~cm}^{-1}\right)$ and $\mathrm{N}-\mathrm{H}\left(3200 \mathrm{~cm}^{-1}\right)$ appeared. These facts suggest that the polymer 6 released tert-butyl group by heating above $190^{\circ} \mathrm{C}$ and tautomerized to poly(6-vinyluracil) that was stable to $350^{\circ} \mathrm{C}$. 


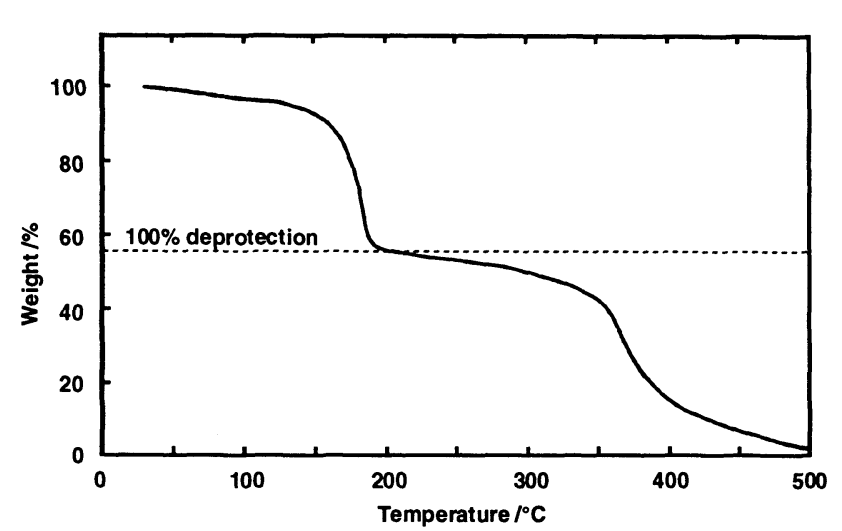

Fig. 4. TGA cueves of polymer 6 .

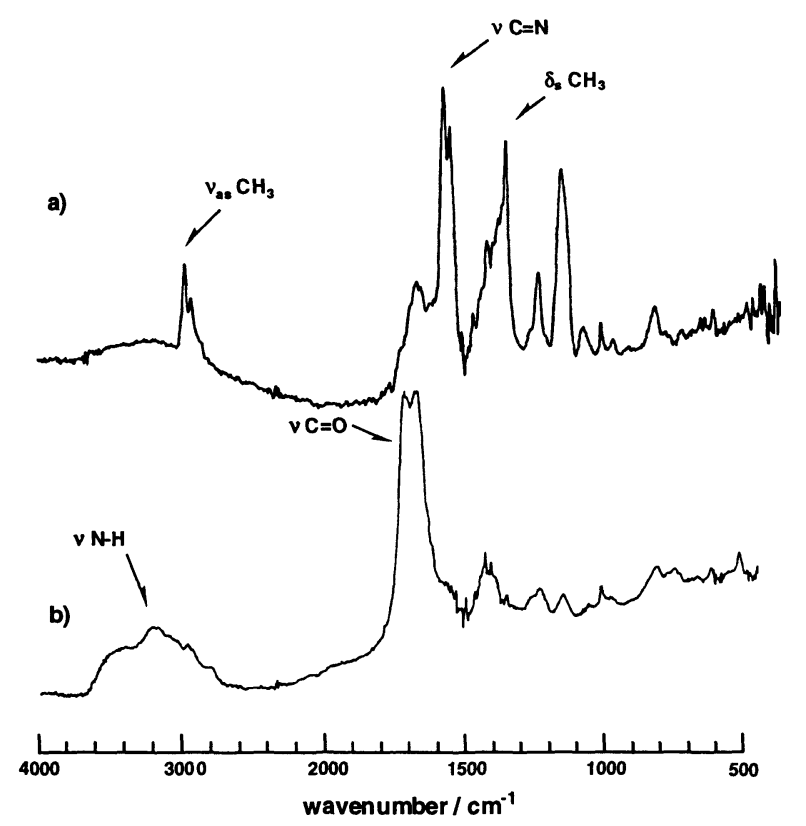

Fig.5. IR spectra of the polymer 6, (a) before and (b) after heating at $200^{\circ} \mathrm{C}$ for $3 \mathrm{~min}$.

\section{3. Sensitivity to Photo-Acid}

The polymer 6 and the acid generator (triphenylsulfonium triflate) were dissolved in chloroform, and the mixture was casted on HMDS-treated silicon wafer to obtain resist film. Photosensitivity of the resist film was investigated by deep-UV light irradiation at $250 \mathrm{~nm}$. After UV irradiation and PEB at $150^{\circ} \mathrm{C}$ for $3 \mathrm{~min}$, absorbances of tert-butyl group (2962 and $\left.1365 \mathrm{~cm}^{-1}\right)$ and pyrimidine $\left(1580 \mathrm{~cm}^{-1}\right)$ disappeared, and new peaks of uracil (3200 and 1720 $\mathrm{cm}^{-1}$ ) appeared (Figure 6). It is similarly to the case of heating at $200^{\circ} \mathrm{C}$ without an acid generator. This fact suggests that the generated acid by UV irradiation promoted releasing of tert-butyl group and the structure changed from enol ether form to keto form as shown in Figure 7, because of the polymer 6 was stable to $190^{\circ} \mathrm{C}$ without an acid generator.

Polymer 6 is insoluble in water, but the polymer 7

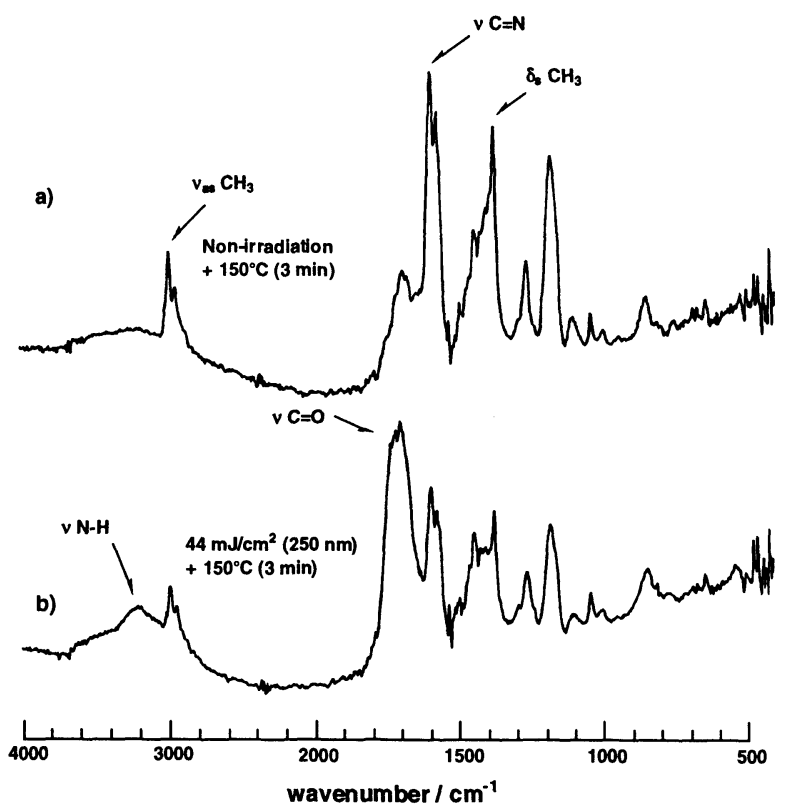

Fig. 6. IR spectra of the polymer 6, (a) no irradiation with PEB and (b) after irradiation with PEB.
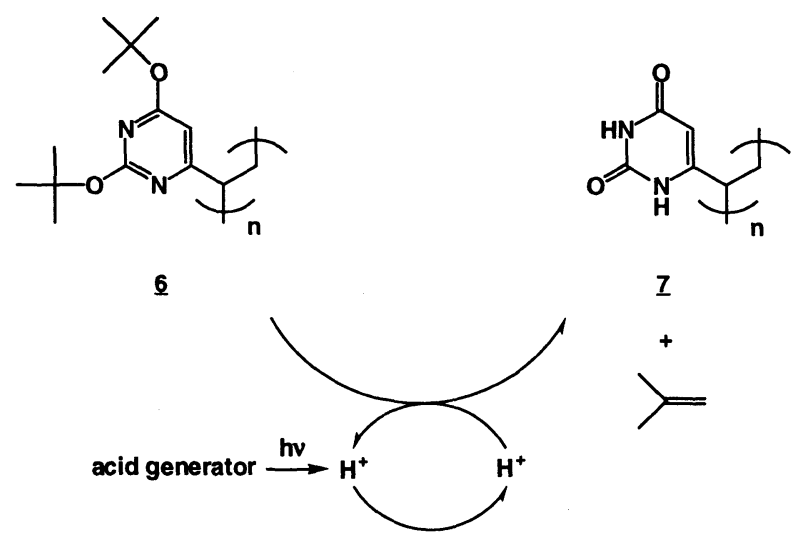

$\underline{7}$

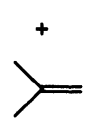

Fig. 7. Chemical amplification of polymer 6 .

containing uracil unit is soluble in aqueous alkaline solution, because pKa value of uracil is aroud 8 . Therefore, the solubility of the polymer 7 after irradiation should be significantly different from that of the polymer 6 before irradiation in both polar (TMAHaq) and nonpolar (anisole) solvents.

\section{4. Positive Type Photoresist}

The resist film should be serve for a positive type photoresist using TMAH aq as a developper. The post exposure baking (PEB) condition of the resist film was investigated for a positive type development. After UV light irradiation $\left(250 \mathrm{~nm}, 50 \mathrm{~mJ} / \mathrm{cm}^{2}\right), P E B$, and development with $3.0 \mathrm{wt} \%$ TMAH aq, the remaining film thickness was measured (Figure 8). No irradiated film (dot line) was insoluble until $3 \mathrm{~min}$ PEB at $150^{\circ} \mathrm{C}$, and after that, the solubility of the film slightly increased. Irradiated $(250 \mathrm{~nm}, 50 \mathrm{~mJ} /$ 
$\mathrm{cm}^{2}$ ) film (solid line), however, became slightly soluble even after PEB at $100^{\circ} \mathrm{C}$ and soluble completely under the condition of PEB at $150^{\circ} \mathrm{C}$ for $3 \mathrm{~min}$. So the PEB $\left(150^{\circ} \mathrm{C}\right.$ for $\left.3 \mathrm{~min}\right)$ condition must result in the highest sensitive resist for a positive type photoresist.

Figure 9 shows the normalized remaining film thickness against irradiated energy using the PEB condition. The sensitivity of the positive type resist using $3.0 \mathrm{wt} \%$ TMAHaq as a developper was $50 \mathrm{~mJ} / \mathrm{cm}^{2}$, and the contrast $(\gamma)$ was 4.3 . The gentle decreasing of film thick-

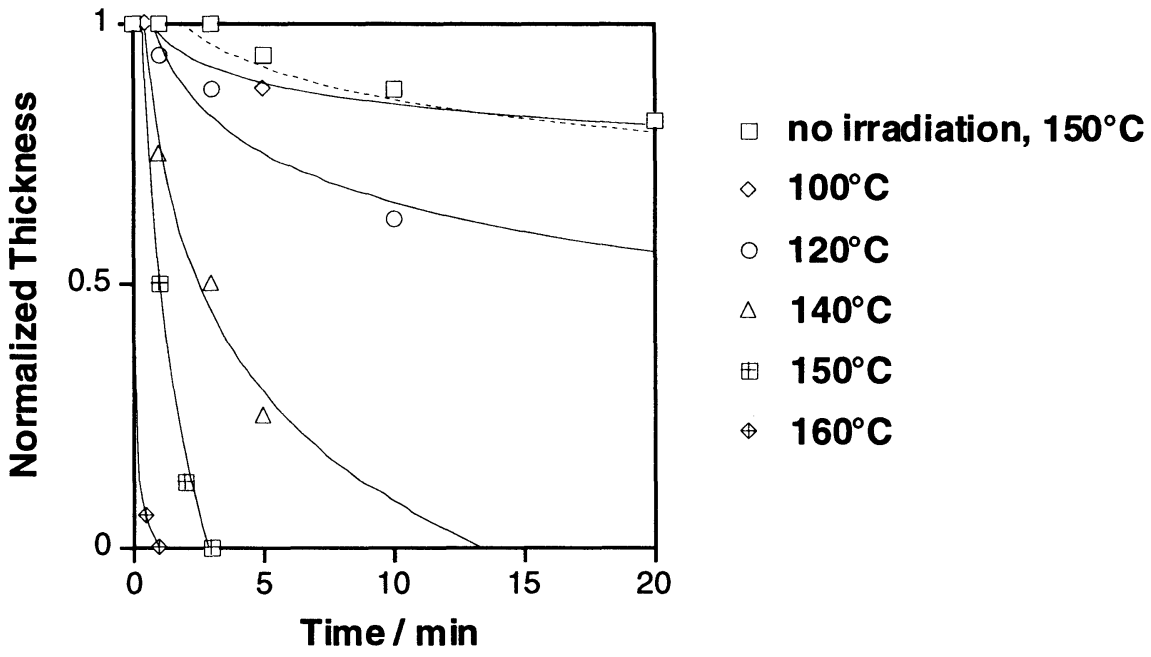

Fig. 8. Remaining film thickness after UV light irradiation $(250 \mathrm{~nm}, 50$ $\mathrm{mJ} / \mathrm{cm}^{2}$ ), PEB at various temperature, and development with $3.0 \mathrm{wt} \%$ TMAH aq.

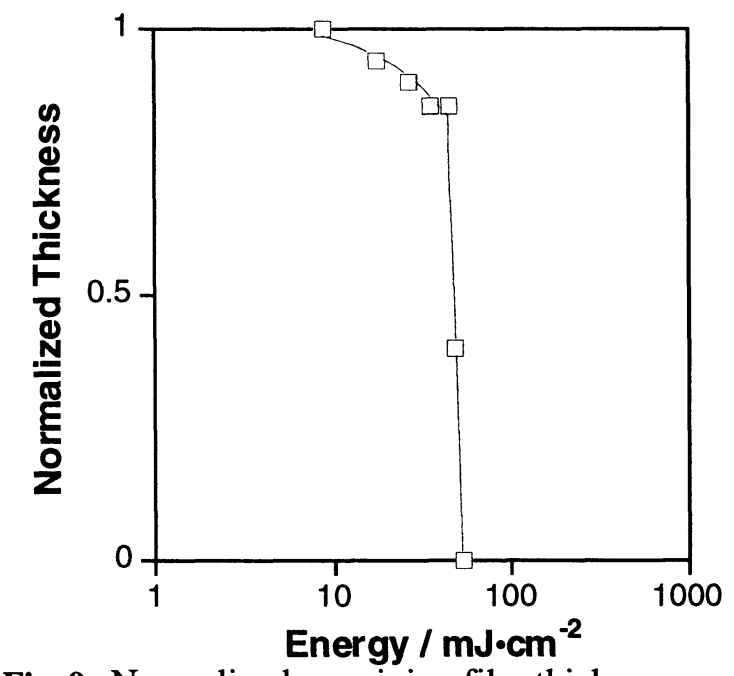

Fig. 9. Normalized remaining film thickness against irradiated energy using the PEB condition using 3.0 wt\% TMAH aq as a developper.

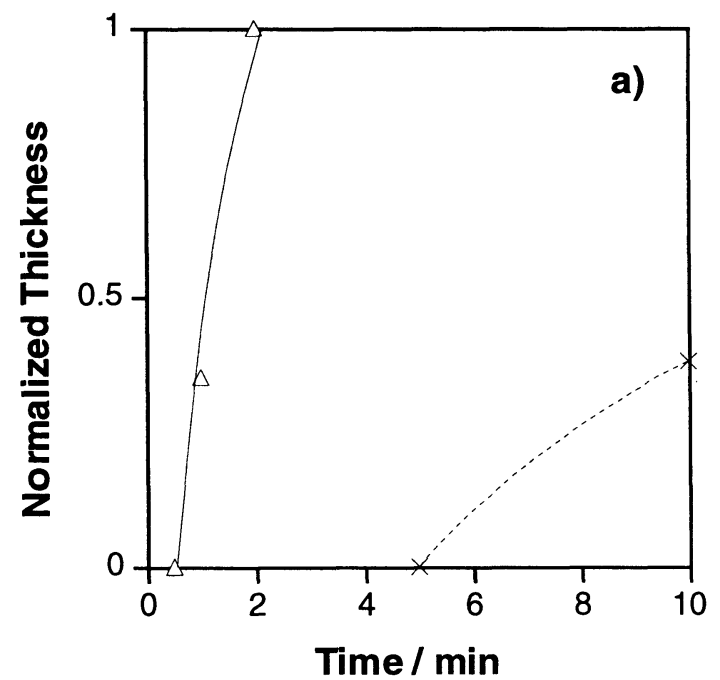

ness at the lower exposing energy would be due to the weight decrease by releasing of tert-butyl group.

\section{5. Negative Type Photoresist}

The resist film should be serve for a negative type photoresist using anisole as a developper. The PEB condition of the resist film was investigated for a negative type development. After UV light irradiation $\left(250 \mathrm{~nm}, 50 \mathrm{~mJ} / \mathrm{cm}^{2}\right)$, PEB $\left(140\right.$ or $\left.150^{\circ} \mathrm{C}\right)$, and development with anisole, the remaining film thickness was measured (Figure 10). No irradiated film (dotted line) was soluble completely until 5 min under the conditon of PEB at $140^{\circ} \mathrm{C}$, and after that, the film became sligjtly insoluble (Figure 10a). Irradiated film $\left(250 \mathrm{~nm}, 50 \mathrm{~mJ} / \mathrm{cm}^{2}\right)$, however, became insoluble completely under the condition of PEB at $140^{\circ} \mathrm{C}$ for $2 \mathrm{~min}$ (Figure 10a). Under the condition

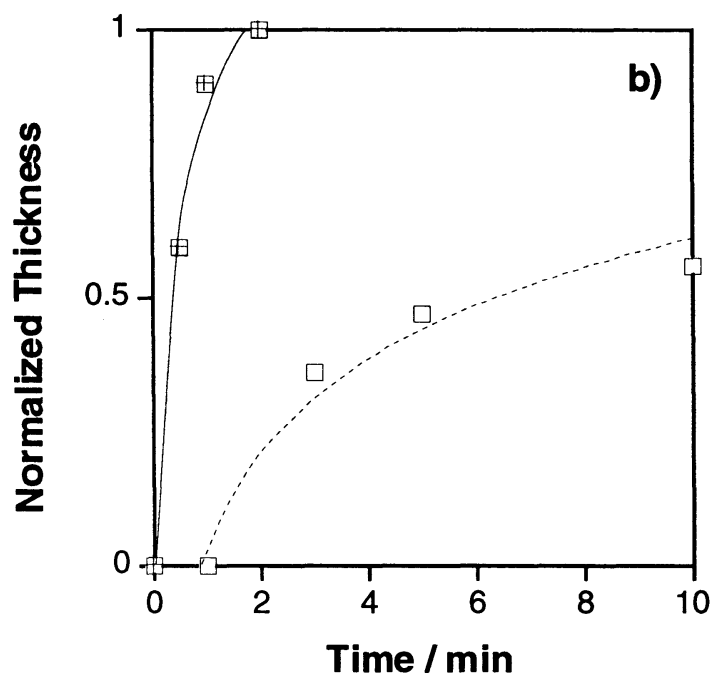

Fig. 10. Normalized remaining film thickness against PEB time. PEB (a) at $140{ }^{\circ} \mathrm{C}$ and (b) at $150{ }^{\circ} \mathrm{C}, \mathrm{UV}$ irradiation at $250 \mathrm{~nm}, 50 \mathrm{~mJ} / \mathrm{cm}^{2}$. 
of PEB at $150^{\circ} \mathrm{C}$ (Figure 10b), on the other hand, no irradiated film (dotted line) became insoluble even for $1 \mathrm{~min}$ PEB. So the PEB condition of $140^{\circ} \mathrm{C}$ for 2 min must result in the highest sensitive resist for a negative type.

Figure 11 shows the normalized remaining film thickness against irradiation energy using the PEB condition $\left(140^{\circ} \mathrm{C}, 2 \mathrm{~min}\right)$. The sensitivity of the negative type resist using anisole as a developper was 35 $\mathrm{mJ} / \mathrm{cm}^{2}$, and the contrast $(\gamma)$ was 8.0.

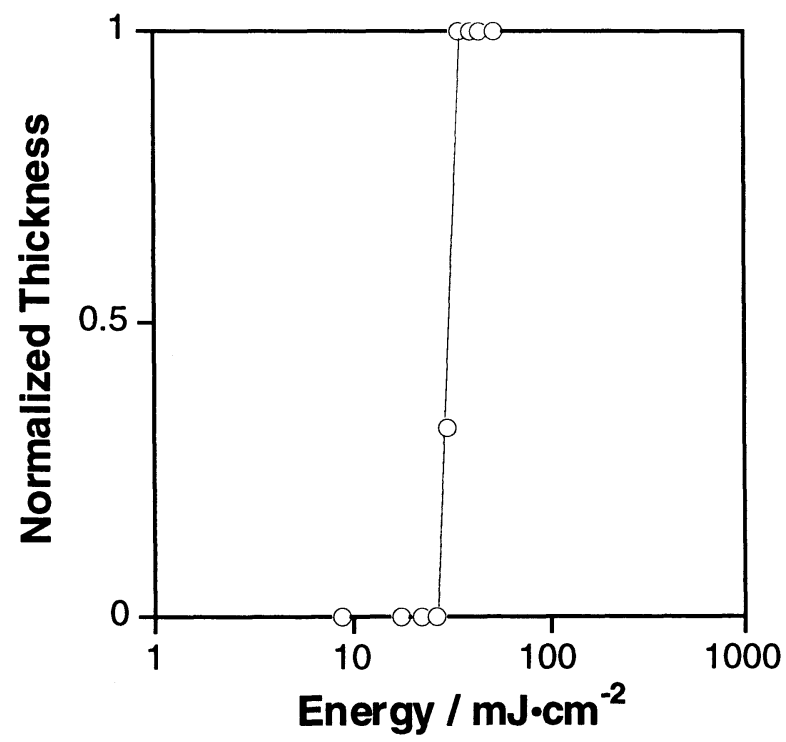

Fig. 11. Normalized remaining film thickness against irradiation energy using the PEB condition $\left(140^{\circ} \mathrm{C}\right.$, 2 min) using anisole as a developper.

\section{Conclusion}

It was revealed that the enol ether derivative (polymer 6) of poly(6-vinyluracil) (polymer 7) was synthesized. The polymer released completely tert-butyl groups above $190^{\circ} \mathrm{C}$ and gave poly(6-vinyluracil) which was stable to $350^{\circ} \mathrm{C}$. The resist film as spin coated from chloroform solution containing photoacid generator released completely the tert-butyl groups after UV light irradiation and following post exposure baking. The solubility of polymer $\mathbf{6}$ after UV irradiation was significantly different from the original polymer in both polar (TMAH aq) and nonpolar (anisole) solvents. The resist film of polymer 6 was found to have high sensitivity and high contrast as both positive and negative type deep-UV resist materials.

\section{References}

1 J. Eisinger, and A. A. Lamola, Mol. Photochem., 1 (1969) 209.

2 D. Wienblum, Photochem. Photobiol., 12 (1970)
509.

3 T. Sugiki, T. Wada, and Y. Inaki, J. Photopolym. Sci. Tecnol., 8 (1995) 9.

4 Y. Inaki, Y. Wang, and K. Takemoto, J. Photopolym. Sci. Tecnol., 4 (1991) 259.

5 Y. Inaki, Y. Wang, T. Saito, and K. Takemoto, J. Photopolym. Sci. Tecnol., 5 (1992) 567.

6 Y. Inaki, Y. Wang, M. Kubo, and K. Takemoto, "Chemistry of Functional Dyes", Z. Yoshida and Y. Shirota, Eds, Mita, Osaka, (1993) p. 365.

7 N. Tohnai, T. Sugiki, E. Mochizuki, T. Wada, and Y. Inaki, J. Photopolym. Sci. Tecnol., 7 (1994) 91.

8 Y. Inaki, M. J. Moghaddam, and K. Takemoto, "Polymers in Microlithography Materials and Process", E. Reichmainis, S. A. Macdonald, and T. Iwayanagi Eds, ACS Sym. Ser., 412 (1989) p. 303.

9 Y. Inaki, N. Matsumura, K. Kanbara, and K. Takemoto, "Polymers for Microelectronics", Y. Tabata, I. Mita, S. Nonogaki, K. Horie, and S. Tagawa, Eds, Kodansya-VCH, (1990) p. 91.

10 Y. Inaki, Polymer News, 17 (1992) 363.

11 Y. Inaki, J. Syn. Org. Chem. Jpn., 51 (1993) 188.

12 Y. Inaki, N. Matsumura, and K. Takemoto, "Polymers for Microelectronics", L. F. Thompson, G. Willson, and S. Tagawa, Eds, ACS Sym. Ser., 537 (1994) p. 142.

13 Y. Inaki, S. Fukunaga, Y. Suda, and K. Takemoto, J. Polymer Sci., Polymer Chem. Ed., 24 (1986) 119.

14 Y. Inaki, M. J. Moghaddam, K. Kanbara, and K. Takemoto, J. Photopolym. Sci. Tecnol., 1 (1988) 28.

15 M. J. Moghaddam, S. Hozumi, Y. Inaki, and K. Takemoto, J. Polym. Sci. PartA, Polymer Chem., 26 (1988) 3297.

16 Y. Inaki, Polym. Mater. Sci. Eng., 60 (1989) 165.

17 M. J. Moghaddam, S. Hozumi, Y. Inaki, and K. Takemoto, Polymer J., 21 (1989) 203.

18 M. J. Moghaddam, K. Kanbara, S. Hozumi, Y. Inaki, and K. Takemoto, Polymer J., 22 (1990) 369.

19 M. J. Moghaddam, Y. Inaki, and K. Takemoto, Polymer J., 22 (1990) 468.

20 Y. Inaki, H. Horito, N. Matsumura, and K. Takemoto, J. Photopolym. Sci. Tecnol., 3 (1990) 417.

21 H. Horito, Y. Inaki, and K. Takemoto, $J$. Photopolym. Sci. Tecnol., 4 (1991) 33.

22 Y. Inaki, Polym. Mater. Sci. Eng., 66 (1992) 109. 